\title{
Protection against the Toxic Effects of Hyperbaric Oxygen by Intermittent Exposure to Reduced Oxygen Pressures
}

\author{
JOHN H. MILLER AND STANLEY A. MENDOZA ${ }^{(23)}$ \\ Department of Pediatrics, Division of Pediatric Nephrology, University of California, San Diego, La Jolla, \\ California, USA
}

\begin{abstract}
Summary
The isolated urinary bladder of the toad was used to compare the effects on $\mathrm{O}_{2}$ toxicity of 1-min and 5-min intermittent normoxic exposures during a prolonged period of hyperoxic exposure (OHP). Various intermittent exposure schedules were tested at 5 atmospheres (ATA) including 4-1 (4 min $100 \% \mathrm{O}_{2}$ followed by 1 min $4 \% O_{2}$ ) 6-1, 9-1, 10-5, 15-5, and 20-5. With all schedules tested, intermittent normoxic exposure significantly protected the SCC (active sodium transport) against the inhibition by 5 ATA of $O_{2}$. Two intermittent schedules (4-1 and 15-5) were tested at $10 \mathrm{ATA}$ using $4 \% \mathrm{O}_{2}$ for the reduced $\mathrm{O}_{2}$ pressure exposure. A significant decrease in the rate of SCC inhibition was observed using both intermittent exposure schedules. The observed SCC protection by intermittent exposure (at 5 and 10 ATA) was not entirely a result of the decreased time of exposure to OHP. Four intermittent schedules were tested at 5 ATA, and the effects of intermittent oxygenation on the SCC were compared with the effects of continuous normoxic exposure. During a 5-hr exposure period, no significant SCC stimulation occurred using a 2-1, 4-1, or 9-1 intermittent schedule. Using a 5-5 intermittent schedule, however, a significant stimulation of SCC was observed at 4 and $5 \mathrm{hr}$. It was concluded that intermittent normoxic exposures as short as $1 \mathrm{~min}$ can afford significant protection against $\mathrm{O}_{2}$ toxicity.
\end{abstract}

\section{Speculation}

Pulmonary oxygen toxicity often limits the treatment of respiratory distress syndrome. Intermittent normoxic periods as brief as $1 \mathrm{~min}$ can be protective against in vitro oxygen toxicity. This, combined with the previous demonstration that intermittent normoxia is protective against pulmonary oxygen toxicity in man suggests that brief intermittent periods of air breathing might decrease the incidence of bronchopulmonary dysplasia in infants requiring oxygen therapy.

Oxygen at high partial pressures (OHP) has been used effectively in pediatric medicine to treat premature infants with respiratory distress syndrome (RDS). OHP has also been used to treat anaerobic bacterial infections, carbon monoxide poisoning, severe burns, and decompression sickness (20). The extensive use of OHP therapy in humans is restricted by the development of oxygen toxicity. In man, prolonged inspiration of $\mathrm{O}_{2}$ at pressures of 1 ATA or greater causes bronchopulmonary dysplasia and convulsions (13). Studies in animals and man have demonstrated that the development of $\mathrm{O}_{2}$ toxicity can be delayed or prevented by interposing short periods of normoxia at regular intervals during a period of hyperoxic exposure $(1,4,8,11,12$, 17). These studies used $5 \mathrm{~min}$ or more of normoxic exposure between hyperoxic exposures. In the treatment of premature infants with RDS by hyperoxic exposure, intermittent 5-min exposures to normoxic gas may be inappropriately long, resulting in severe hypoxemia.

In the present study using the isolated urinary bladder of the toad, the effects on $\mathrm{O}_{2}$ toxicity of 1-min and 5-min intermittent normoxic exposures were compared during a prolonged period of hyperoxic exposure. Continuous exposure of the toad bladder to $\mathrm{O}_{2}$ at pressures of 2 ATA or greater reversibly inhibits active sodium transport (short circuit current) across the bladder $(2,3$, 16). OHP exposure of the toad bladder was regularly interrupted by 1 - or 5 -min exposures to reduced $\mathrm{O}_{2}$ pressures. Various schedules of intermittent exposure were tested at 5 and 10 ATA. In all cases, intermittent exposure of the toad bladder to reduced $\mathrm{O}_{2}$ pressures delayed the onset and reduced the extent of sodium transport inhibition by OHP. One intermittent schedule actually caused a significant stimulation of sodium transport across the bladder when compared with continuous normoxic exposure. It was concluded that 1-min intermittent normoxic exposures were highly effective in protecting the toad bladder sodium transport system from the inhibitory effects of OHP.

\section{MATERIALS AND METHODS}

Experiments were performed on urinary bladders from adult female toads (Bufo marinus). The toads originated from either Colombia, South America (Tarpon Zoo, FL) or from Texas (Mogul-Ed Company, WI) and were kept without feeding on sawdust moistened with tap water. One lobe of the toad bladder (hemibladder) was removed from the animal and mounted in a short circuit current (SCC) apparatus which isolates two contiguous $3.2 \mathrm{~cm}^{2}$ areas (quarterbladders) of the same tissue $(18$, 19). One quarterbladder area served as a control for the experimental manipulation of the other. Quarterbladder areas were bathed on the mucosal and serosal sides by Ringer solutions which were mixed and aerated by bubbling gas through the solutions. The Ringer solution $\left(207 \mathrm{mOsm} / \mathrm{Kg} \mathrm{H}_{2} \mathrm{O}\right)$ was phosphate-buffered at $\mathrm{pH} 8.5$ (after gassing) and contained $90 \mathrm{mM}$ $\mathrm{NaCl}, 5 \mathrm{mM} \mathrm{NaHCO}, 3 \mathrm{mM} \mathrm{KCl}, 1 \mathrm{mM} \mathrm{CaCl}, 0.5 \mathrm{mM}$ $\mathrm{MgSO}_{4}, 2 \mathrm{mM} \mathrm{KH}_{2} \mathrm{PO}_{4}, 1.2 \mathrm{mM} \mathrm{Na} \mathrm{HPO}_{4}$, and $5.5 \mathrm{mM}$ glucose

The SCC across epithelial membranes is equal to net sodium ion flux under various experimental conditions $(14,19)$. It was assumed in this study that the SCC measured under hyperbaric conditions was equal to net sodium ion flux across the bladder. Bladders were kept open circuited except during the brief time required to measure SCC. The potential difference across the bladder was measured concurrently with SCC. Fluctuations in SCC were always associated with similar changes in potential difference. After a hemibladder was mounted in the SCC apparatus, the Ringer solutions bathing the bladder were bubbled with $\mathrm{O}_{2}$ at 1 ATA for at least $1 \mathrm{hr}$ before the start of the experiment to allow the SCC to stabilize. After stabilization, the SCC tended to increase slowly with time in the absence of 
experimental perturbation. Hemibladders with a potential difference of less than $10 \mathrm{mV} 1 \mathrm{hr}$ after mounting were not used in the experiments.

All experiments were performed in a specially designed hyperbaric system which has been previously described (15). Bladder bathing solutions were bubbled with gas mixtures containing either $100 \% \mathrm{O}_{2}, 20 \% \mathrm{O}_{2}$, or $4 \% \mathrm{O}_{2}$. Gas mixtures with less than $100 \% \mathrm{O}_{2}$ contained $\mathrm{N}_{2}$ as the inert gas. The type of gas delivered to either the experimental or control bladder area bathing solutions could be rapidly changed at ambient pressure by the manual operation of an experimental or control gas selector switch located outside the pressure chamber. Ambient pressure is the pressure surrounding the bladder and was equal to 1,5 , or 10 ATA. The partial pressure of $\mathrm{O}_{2}$ in the bladder bathing solution was monitored using a Clark oxygen probe (YSI 4004). $\mathrm{O}_{2}$ determinations were made in one representative experiment and were not repeated in subsequent experiments.

SCC values were normalized by dividing by the SCC measured immediately before pressurization. The data in Figures 2 and 3 (mean $\pm \mathrm{SE}$ ) are expressed as the ratio (intermittent $\mathrm{O}_{2} /$ continuous $\mathrm{O}_{2}$ ) of the normalized SCC values. The data in Figure 4 are expressed as the ratio (intermittent $\mathrm{O}_{2}$ /continuous normoxia) of the normalized SCC values. Student's paired $t$-test and the Wilcoxon signed-rank test were used to determine the significance of the data.

\section{RESULTS}

\section{EFFECT OF CONTINUOUS $\mathrm{O}_{2}$ EXPOSURE ON SCC}

Continuous exposure of isolated toad bladders to $\mathrm{O}_{2}$ at high pressure causes an inhibition of SCC compared to control bladder areas exposed to air at high pressure $(2,3,16)$. The extent of SCC inhibition is dependent on the $\mathrm{O}_{2}$ pressure and the length of exposure. In one representative group of hemibladders, the mean SCC was inhibited $43 \pm 6 \%$ relative to control bladder areas after $5 \mathrm{hr}$ of exposure to $\mathrm{O}_{2}$ at 5 ATA (n $=13, P$ $<0.001$ ). In a similar experiment performed at $10 \mathrm{ATA}, 4 \mathrm{hr}$ of exposure of hemibladders to $\mathrm{O}_{2}$ inhibited the SCC $81 \pm 3 \%$ relative to control bladder areas exposed to $10 \mathrm{ATA}$ of air $(\mathrm{n}=$ $8 ; P<0.001)$. The first significant inhibition of SCC by OHP occurred after $1.5 \mathrm{hr}$ at 5 ATA $(P<0.05)$ and $0.5 \mathrm{hr}$ at 10 ATA $(P<0.005)$ in the above experiments $(16)$.

\section{RINGER OXYGEN PRESSURE FLUCTUATIONS DURING INTERMITTENT OXYGENATION}

Regular interruption of $\mathrm{O}_{2}$ exposure of hemibladders by short periods of normoxic gassing caused a cyclical rise and fall in oxygen pressure in the Ringer solutions bathing the bladder (Fig. 1). After manually switching the type of gas delivered to the bathing solution, a period of $1.5 \mathrm{~min}$ was required to clear residual gas from the gassing line. This $1.5-\mathrm{min}$ period accounts for the delay between the start of normoxic gassing and the fall in Ringer $\mathrm{O}_{2}$ pressure. At 5 ATA the lowest $\mathrm{O}_{2}$ pressure recorded in the bathing solution after a 1 -min period of normoxic gassing was $1260 \mathrm{~mm} \mathrm{Hg}\left(1.66\right.$ ATA of $\mathrm{O}_{2}$ ). When the period of normoxic gassing was $5 \mathrm{~min}$, the $\mathrm{O}_{2}$ pressure of the Ringer solution was normoxic $(152 \mathrm{~mm} \mathrm{Hg}$ ) for $2 \mathrm{~min}$. The rate of equilibration of the gas in the Ringer solution with the bubbled gas was partially dependent on the bubbling rate. This was maintained at approximately 5 bubbles/sec in all experiments.

\section{INTERMITTENT $\mathrm{O}_{2}$ EXPOSURE AT 5 ATA}

Various intermittent exposure schedules were tested at 5 ATA including 4-1 (4 min $100 \% \mathrm{O}_{2}$ followed by $1 \mathrm{~min} 4 \% \mathrm{O}_{2}$ ), 6-1, 9-1, 10-5, 15-5, and 20-5. The effect of each intermittent schedule on the SCC of the experimental bladder areas was compared to the effect of continuous $\mathrm{O}_{2}$ exposure on the SCC of the paired control bladder areas (Fig. 2). With all schedules

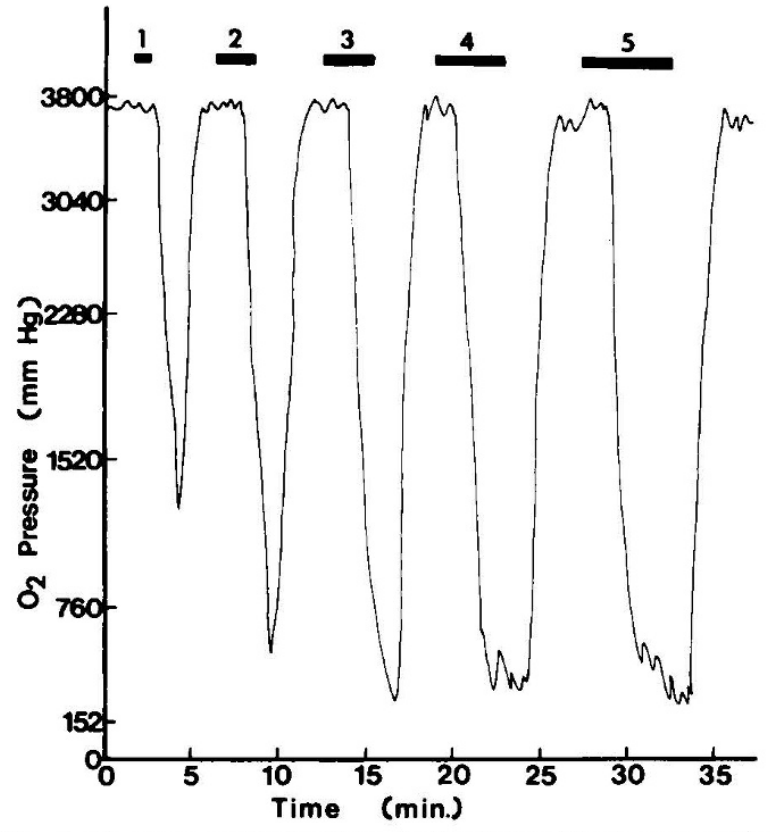

Fig. 1. $\mathrm{O}_{2}$ pressure fluctuations during intermittent oxygenation at 5 ATA. $\mathrm{O}_{2}$ pressures in Ringer solution bathing one bladder area were measured continuously at 5 ATA as described under Materials and Methods. The solution was bubbled at 5 ATA with $100 \% \mathrm{O}_{2}$ beginning at time 0 . Intermittent periods of $4 \% \mathrm{O}_{2}$ gassing are indicated at the top of the figure by horizontal bars. The number above each bar represents the time in minutes of normoxic gassing. The $\mathrm{O}_{2}$ pressure scale (ordinate) is not linear above $2280 \mathrm{~mm} \mathrm{Hg}$, presumably because of saturation of the $\mathrm{O}_{2}$ electrode at $\mathrm{O}_{2}$ pressures above 3 ATA. Corrections for the partial pressure of water vapor $\left(47 \mathrm{~mm} \mathrm{Hg}\right.$ at $\left.37^{\circ}\right)$ have not been made.

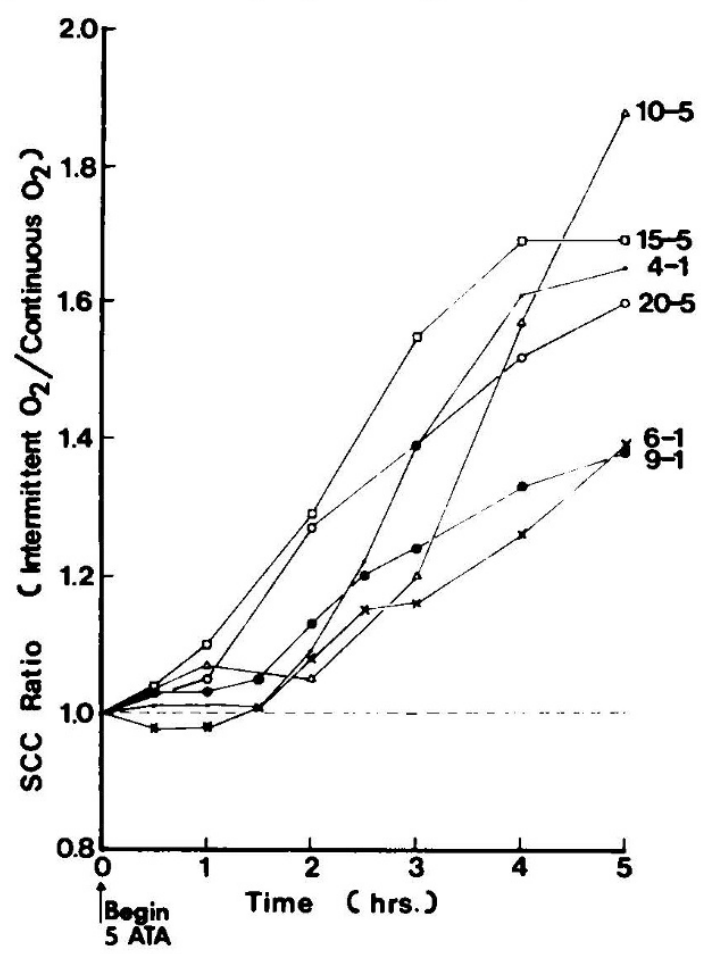

Fig. 2. Protection against $\mathrm{O}_{2}$ toxicity at 5 ATA by intermittent normoxic exposure. Experimental hemibladder areas were exposed to 5 ATA of $100 \% \mathrm{O}_{2}$, alternated with intermittent periods of $4 \% \mathrm{O}_{2}$ exposure at 5 ATA using the following schedules: $10-5(\triangle ; n=8)$, 15$5(\square ; n=7), 20-5(O ; n=8), 4-1(\bullet ; n=14), 6-1,(\times ; n=8)$, and 9. $1(0 ; n=21)$. Control hemibladder areas were continuously exposed to $100 \% \mathrm{O}_{2}$ at 5 ATA. Data are expressed as the mean ratio (experimental/control) of the normalized SCC values. The time of exposure includes both $100 \% \mathrm{O}_{2}$ and $4 \% \mathrm{O}_{2}$ time. Vertical $\mathrm{SE}$ bars have been omitted for clarity. The dashed line is for reference only. 
Table 1. Effect of intermittent and continuous hyperbaric $\mathrm{O}_{2}$ exposure on toad bladder $\mathrm{SCC}^{1}$

\begin{tabular}{|c|c|c|c|c|c|c|c|c|}
\hline & \multirow{2}{*}{$\underset{100 \% \mathrm{O}_{2}-4 \% \mathrm{O}_{2}}{\mathrm{Min}}$} & \multirow[b]{2}{*}{$n$} & \multicolumn{2}{|c|}{$\mathrm{SCC}_{\mathrm{pp}}(\mu \mathrm{A})$} & \multicolumn{2}{|c|}{$\mathrm{SCC}_{\sqrt{ }} / \mathrm{SCC}_{\mathrm{pp}}$} & \multirow[b]{2}{*}{$\mathrm{I} / \mathrm{C}$} & \multirow[b]{2}{*}{$\boldsymbol{P}$} \\
\hline & & & Continuous & Intermittent & Continuous (C) & Intermittent (I) & & \\
\hline \multirow[t]{6}{*}{$5 \mathrm{ATA}, \mathrm{t}=5 \mathrm{hr}$} & $10-5$ & 8 & $35 \pm 6$ & $31 \pm 5$ & $1.85 \pm 0.43$ & $3.06 \pm 0.48$ & $1.88 \pm 0.22$ & $<0.01$ \\
\hline & $15-5$ & 7 & $59 \pm 7$ & $51 \pm 6$ & $0.78 \pm 0.10$ & $1.26 \pm 0.12$ & $1.69 \pm 0.11$ & $<0.001$ \\
\hline & $20-5$ & 8 & $74 \pm 17$ & $68 \pm 15$ & $0.62 \pm 0.11$ & $0.95 \pm 0.14$ & $1.60 \pm 0.14$ & $<0.005$ \\
\hline & 4-1 & 14 & $81 \pm 15$ & $72 \pm 9$ & $0.93 \pm 0.11$ & $1.45 \pm 0.18$ & $1.65 \pm 0.14$ & $<0.001$ \\
\hline & $6-1$ & 8 & $86 \pm 7$ & $89 \pm 13$ & $0.79 \pm 0.09$ & $1.09 \pm 0.14$ & $1.39 \pm 0.06$ & $<0.001$ \\
\hline & $9-1$ & 21 & $70 \pm 9$ & $71 \pm 12$ & $1.08 \pm 0.09$ & $1.44 \pm 0.14$ & $1.38 \pm 0.12$ & $<0.005$ \\
\hline \multirow[t]{2}{*}{$10 \mathrm{ATA}, \mathrm{t}=4 \mathrm{hr}$} & $15-5$ & 8 & $68 \pm 10$ & $62 \pm 7$ & $0.42 \pm 0.04$ & $0.56 \pm 0.05$ & $1.35 \pm 0.09$ & $<0.01$ \\
\hline & 4-1 & 8 & $100 \pm 14$ & $109 \pm 18$ & $0.41 \pm 0.06$ & $0.51 \pm 0.05$ & $1.33 \pm 0.09$ & $<0.01$ \\
\hline
\end{tabular}

${ }^{1}$ See Figures 2 and 3 for experimental details. SCC : SCC measured immediately before pressurization; SCC: SCC measured 4 or 5 hr after pressurization. $\mathrm{SCC}_{\mathrm{t}} / \mathrm{SCC}_{\mathrm{pp}}$ is the normalized $\mathrm{SCC}$ which is used to calculate the ratio $\mathrm{I} / \mathrm{C}$. Data are expressed as the mean $\pm \mathrm{SE}$. Significance was determined using the paired $t$-test.

Table 2. Analysis of protection ratio $(I / C)$ in terms of $O H P$ exposure time ${ }^{1}$

\begin{tabular}{|c|c|c|c|c|c|}
\hline & $\underset{100 \% \mathrm{O}_{2}-4 \% \mathrm{O}_{2}}{\text { Min }}$ & $n$ & $\begin{array}{c}\text { OHP ex- } \\
\text { posure, } \\
\text { hr }\end{array}$ & $\mathrm{I} / \mathrm{C}$ & \\
\hline \multirow[t]{6}{*}{5 ATA } & $10-5$ & 8 & 3.3 & $1.18 \pm 0.11$ & $>0.05$ \\
\hline & $15-5$ & 7 & 3.8 & $1.48 \pm 0.10$ & $<0.02$ \\
\hline & $20-5$ & 8 & 4.0 & $1.26 \pm 0.12$ & $<0.05$ \\
\hline & $4-1$ & 14 & 4.0 & $1.50 \pm 0.10$ & $<0.01$ \\
\hline & $6-1$ & 8 & 4.3 & $1.38 \pm 0.08$ & $<0.01$ \\
\hline & $9-1$ & 21 & 4.5 & $1.31 \pm 0.11$ & $<0.01$ \\
\hline \multirow[t]{2}{*}{ 10ATA } & $15-5$ & 8 & 3.0 & $1.41 \pm 0.11$ & $<0.01$ \\
\hline & $4-1$ & 8 & 3.2 & $1.43 \pm 0.12$ & $<0.01$ \\
\hline
\end{tabular}

${ }^{1}$ Protection ratios of Table 1 were recalculated in terms of the $100 \%$ $\mathrm{O}_{2}$ exposure time rather than the total exposure time. After $5 \mathrm{hr}(5$ ATA) or $4 \mathrm{hr}$ (10 ATA) of intermittent exposure, the normalized SCC of the bladder areas exposed intermittently to $\mathrm{O}_{2}$ (I) was divided by the normalized SCC of the bladder areas exposed continuously to $\mathrm{O}_{2}$ after an equivalent time of OHP exposure (C). Significance was determined using the Wilcoxon signed-rank test.

tested, intermittent normoxic exposure significantly protected the SCC against the inhibition caused by 5 ATA of $\mathrm{O}_{2}$. In general, the extent of protection of the SCC was greater when the period of normoxic gassing represented a greater fraction of the total time of exposure. This was true whether the normoxic exposure was 1 or $5 \mathrm{~min}$. There was a $1.5-\mathrm{hr}$ lag before significant protection occurred, corresponding with the $1.5-\mathrm{hr}$ latent period before the onset of significant SCC inhibition by continuous exposure to $\mathrm{O}_{2}$ at 5 ATA. A detailed summary of the data from these experiments is presented in Table 1 . There was a general tendency for the SCC to rise following isolation of the bladders. Thus the normalized SCC values in the 5 ATA continuous $\mathrm{O}_{2}$ exposures are in most cases greater than or statistically equal to 1.00 . Consequently, 5 ATA of $\mathrm{O}_{2}$ inhibited the increase in SCC in these bladders without causing an actual fall in SCC from prepressure levels. In an additional set of intermittent oxygenation experiments using air at 5 ATA instead of normoxic gas for the reduced $\mathrm{O}_{2}$ exposure, significant protection of the bladder SCC was again observed. Analysis of the 5 ATA data in terms of the time of exposure to $100 \% \mathrm{O}_{2}(\mathrm{OHP}$ time) rather than the total time $\left(4 \% \mathrm{O}_{2}\right.$ time plus $100 \% \mathrm{O}_{2}$ time) indicated that the observed SCC protection by intermittent exposure was not entirely a result of the decreased time of exposure to OHP (Table 2).

\section{INTERMITTENT $\mathrm{O}_{2}$ EXPOSURE AT 10 ATA}

Two intermittent schedules (4-1 and 15-5) were tested at 10 ATA using $4 \% \mathrm{O}_{2}\left(2\right.$ times normoxia) for the reduced $\mathrm{O}_{2}$

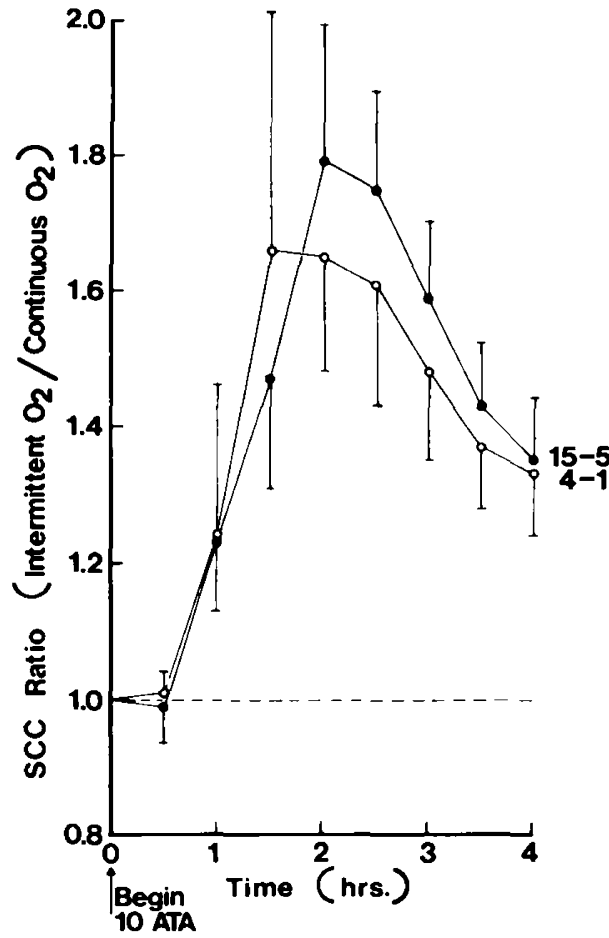

Fig. 3. Protection against $\mathrm{O}_{2}$ toxicity at 10 ATA by intermittent exposure to reduced $\mathrm{O}_{2}$ pressures. Experimental hemibladder areas were exposed to $10 \mathrm{ATA}$ of $100 \% \mathrm{O}_{2}$, alternated with intermittent periods of $4 \% \mathrm{O}_{2}$ exposure at 10 ATA using the following schedules: $15-5(\Theta ; n=8)$, and $4-1(O ; n=8)$. Control hemibladder areas were continuously exposed to $100 \% \mathrm{O}_{2}$ at 10 ATA. Data (mean $\pm \mathrm{SE}$ ) are expressed as the ratio (experimental/control) of the normalized SCC values. Vertical bars represent $\mathrm{SE}$.

pressure exposure (Fig. 3). A significant decrease in the rate of SCC inhibition was observed using both intermittent exposure schedules relative to continuous exposure to $\mathrm{O}_{2}$. Maximum protection of the SCC occurred after $2 \mathrm{hr}$ of intermittent exposure. The 10 ATA protection ratios observed at $2 \mathrm{hr}$ using the $4-1$ schedule $(1.65 \pm 0.17 ; P<0.01)$ and the $15-5$ schedule $(1.79 \pm 0.20 ; P<0.01)$ compared favorably with the maximum 5 ATA protection ratios observed after $5 \mathrm{hr}$ of exposure (Fig. 2). Presumably, the increased rate of SCC inhibition by OHP at 10 ATA, relative to 5 ATA, accounts for the shift in the time of maximum protection from approximately $5 \mathrm{hr}$ at 5 ATA to $2 \mathrm{hr}$ at $10 \mathrm{ATA}$. A summary of the $10 \mathrm{ATA}$ data is presented in Table 1. The observed protection of SCC by intermittent normoxic exposure at 10 ATA resulted only in part from a decrease in the time of exposure to OHP (Table 2). 


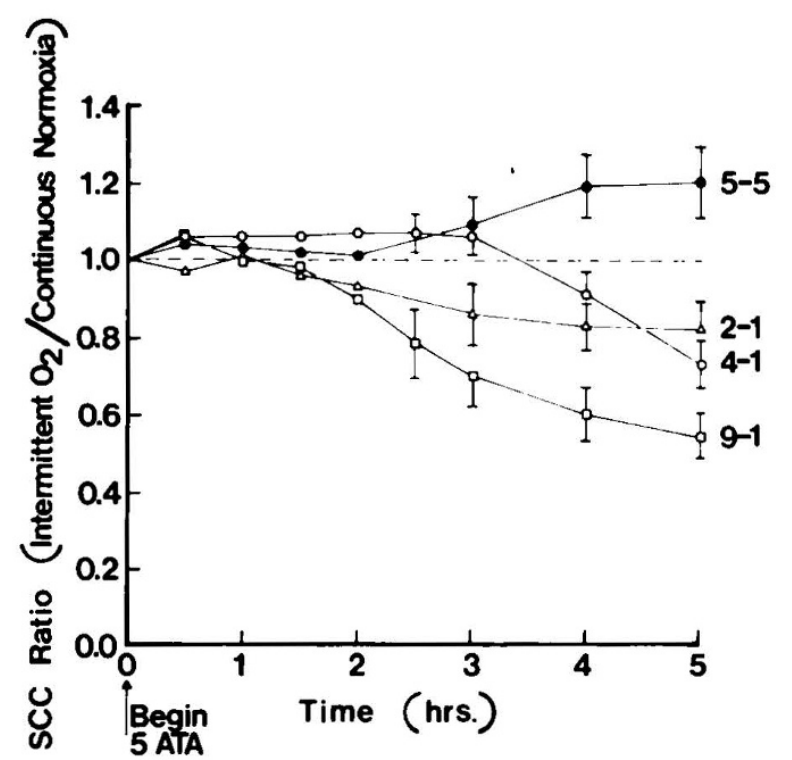

Fig. 4. SCC stimulation by intermittent normoxic exposure at 5 ATA. Experimental hemibladder areas were exposed to 5 ATA of $100 \% \mathrm{O}_{2}$, alternated with intermittent periods of $4 \% \mathrm{O}_{2}$ exposure at 5 ATA using the following schedules: 5-5, 2-1, 4-1, and 9-1. Control hemibladder areas were continuously exposed to $4 \% \mathrm{O}_{2}$ at 5 ATA. Data (mean \pm $\mathrm{SE}$ ) are expressed as the ratio (experimental/control) of the normalized SCC values. SE bars are omitted prior to $2.5 \mathrm{hr}$ of exposure for clarity. The mean prepressure SCC values for the experimental and control bladder areas, respectively, are: $(\bullet) 5-5$ schedule $(n=15) 56 \pm 7$ and $57 \pm 10 \mu \mathrm{A} ;(\triangle) 2-1$ schedule $(n=5) 54 \pm 10$ and $94 \pm 31 \mu \mathrm{A} ;(0) 4$ 1 schedule $(n=15) 95 \pm 19$ and $88 \pm 15 \mu \mathrm{A}$; () $9-1$ schedule $(n=8)$ $42 \pm 9$ and $50 \pm 11 \mu \mathrm{A}$.

\section{SCC STIMULATION BY INTERMITTENT $\mathrm{O}_{2}$ EXPOSURE}

Allen et al. $(2,3)$ reported that $15-75 \mathrm{~min}$ of exposure to 11 ATA $\mathrm{O}_{2}$ caused an increase in the ATP concentration in the toad bladder. Since most ATP produced by the bladder is used to support sodium transport $(9,10)$, it seemed possible that an intermittent oxygenation schedule might actually stimulate the SCC in the toad bladder. Four intermittent schedules were tested at 5 ATA which compared the effects on the SCC of intermittent oxygenation with the effects of continuous normoxic exposure (Fig. 4). During a 5-hr exposure period, no significant SCC stimulation occurred at any time using a $2-1,4-1$, or 9-1 intermittent schedule. Significant SCC inhibition was observed in all three cases by 4 or $5 \mathrm{hr}$ of exposure. Using a 5-5 intermittent schedule, however, a significant stimulation of SCC was observed at 4 and $5 \mathrm{hr}$ relative to continuous normoxic exposure $(\mathrm{n}=15 ; P<0.05)$.

\section{DISCUSSION}

The toxic effects of prolonged $\mathrm{O}_{2}$ exposure create severe problems with the use of OHP for the treatment of respiratory disorders and other oxygen-responsive diseases. Two methods of reducing the harmful effects of OHP without concurrently reducing the beneficial effects have been proposed. These are the administration of chemical protective agents during OHP exposure $(6,7,21)$ or the use of intermittent oxygenation schedules $(1,4,8,11,12,17)$. Both methods are effective in vivo in extending the tolerance of an organism to OHP by delaying the development of oxygen-induced pulmonary and central nervous system damage. Intermittent oxygen exposure in humans at 2 ATA ( $20 \mathrm{~min} \mathrm{O}_{2}-5$ min normoxic gas) significantly delayed the development of pulmonary $\mathrm{O}_{2}$ toxicity (reduction of vital capacity) relative to continuous $\mathrm{O}_{2}$ exposure at $2 \operatorname{ATA}(5,12)$.

In the present study, the effects of intermittent oxygenation relative to continuous oxygenation were investigated in the in vitro toad bladder system. A comparison was made between the effects of 1-min and 5-min intermittent normoxic exposures. In the toad bladder the inhibition of SCC by OHP at 5 ATA (Fig. 2 ) and 10 ATA (Fig. 3) could be delayed and partially prevented by intermittent schedules of $\mathrm{O}_{2}$ exposure. Intermittent normoxic exposures of 1-min duration protected the SCC to about the same extent as 5-min normoxic exposures, provided the period of normoxic gassing represented the same fraction of the total time of $\mathrm{O}_{2}$ exposure. It was concluded that the sodium transport system was protected in part from the inhibitory effects of OHP by intermittent normoxic exposures. The reduced rate and extent of SCC inhibition during intermittent exposure did not result completely from a reduction in the total time of exposure to OHP (Table 2). Although intermittent normoxic exposure delays and decreases the inhibition of SCC by OHP, there is a significant decrease in SCC during the intermittent OHP exposure (Fig. 4).

All of the intermittent schedules tested for SCC protection used ratios of $\mathrm{O}_{2}$ time to normoxic time that were greater than 2.0. One intermittent schedule with a ratio of $1.0\left(5 \mathrm{~min}_{2}-5\right.$ min normoxia) was tested for SCC stimulation by comparing its effects on toad bladder SCC with the effects of continuous normoxic expostire at 5 ATA (Fig. 4). The SCC was stimulated $20 \pm 9 \%$ in bladder areas exposed for $5 \mathrm{hr}$ to a $5-5$ intermittent schedule. It is not known whether this stimulation of SCC resulted from an increase in the ATP concentration in the bladder following OHP exposure $(2,3)$ or whether it was caused by some other mechanism.

It is clear from these studies and from the work of others (1, $4,8,11,12,17)$ that schedules of intermittent normoxic exposure can delay the in vivo and in vitro development of $\mathrm{O}_{2}$ toxicity. Hendricks et al. (12) demonstrated that the use of a 205 intermittent normoxic schedule at 2 ATA in man delays the onset of pulmonary dysfunction, extending the total time OHP can be safely used. In the present study with the toad bladder at 5 ATA, it was shown that the protection against SCC inhibition afforded by a 20-5 intermittent normoxic schedule was similar to the protection afforded by a 4-1 schedule (Fig. 2). This is the first demonstration that normoxic exposures as short as $1 \mathrm{~min}$ can afford significant protection against $\mathrm{O}_{2}$ toxicity. It is interesting that this protection occurred in spite of the fact that the partial pressure of $\mathrm{O}_{2}$ in the bladder bathing solution never fell below $1260 \mathrm{~mm} \mathrm{Hg}$ (Fig. 1). The effects of intermittent oxygenation on sodium transport in the isolated toad bladder may not be directly applicable to the effects of similar intermittent oxygen exposures on the pulmonary and central nervous systems in man. However, the results of these studies of intermittent OHP exposure of the toad bladder are consistent with previously reported in vivo mammalian studies and provide additional information which may be useful in the development of efficient and safe procedures for the therapeutic use of OHP.

\section{CONCLUSION}

The effect of intermittent hyperbaric oxygenation on sodium transport (SCC) across the toad bladder was investigated. At 5 and 10 ATA, intermittent exposure of the bladder to reduced $\mathrm{O}_{2}$ pressure delayed the onset and reduced the extent of SCC inhibition by OHP. At 5 ATA, intermittent 1 -min and 5 -min normoxic exposures were equally effective in protecting the SCC from $\mathrm{OHP}$-induced inhibition. A $5 \mathrm{~min} \mathrm{O}_{2}-5 \mathrm{~min}$ normoxic schedule caused a significant stimulation of SCC compared to the effect of continuous normoxic exposure. It was concluded that the interruption of OHP exposure by intermittent 1 -min normoxic exposures is highly effective in protecting toad bladder sodium transport from the toxic effects of OHP.

\section{REFERENCES AND NOTES}

1. Ackerman, N. B., and Brinkley, F. B.: Cyclical intermittent hyperbaric oxygenation: A method for prolonging survival in hyperbaric oxygen. In: 
Proceedings of the Third International Congress on Hyperbaric Medicine, p. 200 (Williams \& Wilkins, Baltimore, 1966).

2. Allen, J. E., Goodman, D. B. P., Besarab, A., and Rasmussen, H.: Studies on the biochemical basis of oxygen toxicity. Biochim. Biophys. Acta, 320: 708 (1973).

3. Allen, J. E., and Rasmussen, $\mathrm{H}$.: The effects of oxygen on cellular metabolism. Int. J. Clin. Pharmacol. Ther. Toxicol., 5: 26 (1971).

4. Biersner, R. J., Hall, D. A., and Linaweaver, P. G.: Associations between physiological factors and pulmonary toxicity during intermittent oxygen breathing at 2 ATA. Aviat. Space Environ. Med., 47: 173 (1976).

5. Clark, J. M., and Lambertsen, C. J.: Rate of development of pulmonary oxygen toxicity in man during oxygen breathing at 2.0 ATA. J. Appl. Physiol., 30: 739 (1971).

6. Currie, W. D., Gelein, R. M., Jr., and Sanders, A. P.: Effects of hyperbaric oxygenation on metabolism. V. Comparison of protective agents at 5 atmospheres 100\% oxygen. Proc. Soc. Exp. Biol. Med., 132: 660 (1969).

7. Faiman, M. D., Mehl, R. G., and Oehme, F. W.: Protection with disulfiram from central and pulmonary oxygen toxicity. Biochem. Pharmacol., 20: 3059 (1971).

8. Hall, D. A.: Influence of systematic fluctuations of inspired $\mathrm{PO}_{2}$ upon oxygen tolerance (Master's thesis, University of Pennsylvania, 1967).

9. Hardler, J. S.: The control of energy metabolism by sodium transport in the toad urinary bladder. In: Proceedings of the Fifth International Congress on Nephrology, Vol. 2, p. 79 (Karger, Basel, 1974).

10. Handler, J. S., Preston, A. S., and Rogulski, J.: Control of glycogenolysis in the toad's urinary bladder: The effect of anaerobiosis, sodium transport, and arginine vasotocin. J. Biol. Chem., 243: 1376 (1968).

11. Haugaard, N.: Cellular mechanisms of oxygen toxicity. Physiol. Rev., 48: 311 (1968)

12. Hendricks, P. L., Hall, D. A., Hunter, W. L., and Haley, P. J.: Extension of pulmonary $\mathrm{O}_{2}$ tolerance in man at 2 ATA by intermittent $\mathrm{O}_{2}$ exposure. $\mathrm{J}$. Appl. Physiol. (In press, 1977)

13. Lambertsen, C. J.: Effects of oxygen at high partial pressure. In: Handbook

Copyright $(1978$ International Pediatric Research Foundation, Inc. $0031-3998 / 78 / 1204-0283 \$ 02.00 / 0$ of Physiology-Respiration II, Vol. 2, p. 1027 (Williams \& Wilkins, Baltimore, 1965).

14. Mendoza, S. A., Handler, J. S., and Orloff, J.: Effect of inhibitors of sodium transport on response of toad bladder to antidiuretic hormone and cyclic AMP. Amer. J. Physiol., 219: 1440 (1970)

15. Miller, J. H., Hall, D. A., Haworth, D., and Mendoza, S. A.: Hyperbaric system for oxygen toxicity studies in the toad urinary bladder. J. Appl. Physiol., 40: 483 (1976)

16. Miller, J. H., and Mendoza, S. A.: Inhibition of sodium transport by hyperbaric oxygen in the toad urinary bladder. Undersea Biomed. Res. (In press, 1977).

17. Penrod, K. E.: Effect of intermittent nitrogen exposures on tolerance to oxygen at high pressures. Amer. J. Physiol., 186: 149 (1956)

18. Sharp, G. W. G., and Leaf, A.: Biological action of aldosterone in vitro Nature, 202: 1185 (1964).

19. Ussing, H. H., and Zerahn, K.: Active transport of sodium as the source of electric current in the short-circuited isolated frog skin. Acta Physiol. Scand., 23: 110 (1951).

20. Wada, J., and Iwa, T. (eds.): Proceedings of the Fourth International Congress on Hyperbaric Medicine (Williams \& Wilkins, Baltimore, 1970)

21. Wood, J. D.: Oxygen toxicity. In: The Physiology and Medicine of Diving and Compressed Air Work, p. 166 (Williams \& Wilkins, Baltimore, 1975).

22. This research was jointly funded by the Office of Naval Research and the Naval Medical Research and Development Command through the Office of Naval Research Contract N00014-69-A-0200-6050. Additional suppor was contributed by the National Kidney Foundation through a postdoctoral fellowship to J. H. Miller.

23. Requests for reprints should be addressed to: Stanley A. Mendoza, M.D. Department of Pediatrics, M-009, University of California, San Diego, LaJolla, CA 92093 (USA)

24. Received for publication March 23, 1977.

25. Accepted for publication July $13,1977$. 